\title{
Effectiveness of Outcome Based Education (OBE) toward Empowering the Students Performance in an Engineering Course
}

Devasis Pradhan"

IEEE Member, Assistant Professor, Department of Electronics \& Communication Engineering, Acharya Institute of Technology, Bengaluru -560107, India

\author{
DOI: $10.36348 /$ jaep.2021.v05i02.003 $\quad$ | Received: 02.02.2021 | Accepted: 16.02.2021 | Published: 23.02 .2021
}

*Corresponding author: Devasis Pradhan

\section{Abstract}

Outcomes based education (OBE) is the highlighted trend these days in education area to manual students in their professional career and lead them to greater informed and creative. This could help them to development nicely in their working surroundings. To gain the attributes detailed for outcome based totally schooling via NBA right overview techniques are required, due to the fact assessment of the graduate attributes plays a key position in coaching gaining knowledge of system to enhance the device and to improve the overall performance of college students. This procedure will provide idea for the machine to bridge the distance among coaching and final results based totally mastering method. This paper initially lines the roots of final results-based training (OBE) and introduces key standards of implementation. It then proceeds with defining what effects are and discusses how the definition of consequences demands paradigm shift in evaluation and evaluation practices. Subsequently, the paper tackles crucial implications of sporting out the framework for the exercise and strategies of assessment and evaluation of college students ${ }^{\text {ee }}$ performance in engineering college. These implications are meshed with discussion of the four running ideas of OBE.

Keywords: OBE, Outcome based evaluation, Outcome based assessment, Graduate Attributes (GA), Course outcomes (CO), Program Outcomes (PO), Program specific outcomes (PSO) Engineering Pedagogy and Outcome Based Education (EPOBE).

Copyright (C) 2021 The Author(s): This is an open-access article distributed under the terms of the Creative Commons Attribution 4.0 International License (CC BY-NC 4.0) which permits unrestricted use, distribution, and reproduction in any medium for non-commercial use provided the original author and source are credited.

\section{INTRODUCTION}

Earlier educational organization use to awareness on syllabus set by using a few experienced human beings or professional our bodies especially fields, but the ones sort of curriculum didn't paintings properly to offer the graduates with successful carrier in their expert lifestyles. The history of outcome based totally training in traditional instructional system college students are given grades primarily based on how lots they score in the tests carried out for what they are concept in lecture room periods. Right here a few scholar rating nicely and different rating underneath average. In this system this type of variant in rankings of pupil is thought as ordinary and unavoidable.

Outcomes based education (OBE) is a system that includes the restructuring of curriculum, evaluation and reporting practices in training to mirror the achievement of excessive order gaining knowledge and mastery in place of the buildup of path credit" [1]. As a result the number one intention of OBE is to facilitate desired adjustments inside the rookies, with the aid of growing knowledge, developing talents and/or positively influencing attitudes, values and judgment. OBE embodies the idea that the first-rate manner to analyze is to first decide what wishes to be finished. As soon as the goal (product or outcome) has been determined the techniques, tactics, strategies, and different approaches and means may be put into vicinity to achieve the intention.

The OBE comes in the shape of competencybased getting to know requirements and consequencesbased excellent guarantee monitoring. OBE is being identified as the most critical instructional factor of societies with knowledge based economic system. OBE designed to acquire the predefined studying effects. OBE version of accreditation makes a speciality of targets and effects of an engineering programme. OBE begins with a clear photograph of what a student have to be able to do, design the curriculum, teaching- 
mastering technique and evaluation to ensure that the outcomes are attained. OBE version helps non-stop exceptional improvement.

\section{Why Outcomes?}

In all of the current warmness of discussion about OBE rarely is the term 'consequences' described or explored. Neither is it acknowledged that the time period isn't always one in every of abuse in any other arena other than education. A cursory seek at the web for 'consequences definition' yields an impressive array of documents approximately consequences and their use. In essence, an emphasis on effects defines long time, broadly described goals and objectives and holds contributors liable for attaining the ones. The choice of rules, methods and procedures is made by way of members on the idea in their professional judgement" which have to or might be knowledgeable with the aid of applicable studies, practice knowledge and the desires of ail those worried.

Outcome-based education is an method to education in which selections about the curriculum are pushed by using the go out mastering results that the students must show at the end of the direction. The National Board of Accreditation (NBA) has adopted OBE technique and has laid out hints for establishments to pursue excellence with a view to get accreditation. Those recommendations are followed to define the programme results and the direction results.

Engineering education environment in India is one among the biggest inside the global. In the year of 2019 around six thousand institutions are strolling in India providing engineering schooling at diploma, UG and PG stage [2]. With the sort of large quantity of establishments and graduating engineers, the fine of those engineers is likewise a subject for the network as an entire. Bringing in and maintaining the pleasant of training is the mandate of All India Council of Technical Education (AICTE) in India and national Board of Accreditation (NBA).

On the way to make certain excellent guarantee of technical training worldwide, an international Engineering Alliance has been fashioned. There are three agreements referred to as Washington (for engineers), Dublin (for technologist) and Sidney (for technician) Accords covering mutual reputation a few of the agreeing countries. India has come to be permanent signatory member of Washington Accord in 2014, which made it obligatory to undertake outcome based totally training. However NBA had already started out enforcing OBE for the reason since 2009.

\section{Outcome Based Education (OBE)}

OBE has been followed for more than a century while educationalists introduced to light the significance of appreciating students' Character version inside the studying process, believing that training is fine measured by means of encouraging man or woman college students' fulfillment that would occur at exceptional fees for distinct college students.

The objective of OBE is to make certain that rookies are exceptionally ready with knowledge, competencies and attitudes required to end up a successful character once they go out the educational machine. OBE is an educational process that specializes in destiny performance abilities of the novices and to apply knowledge for accomplishing their consequences after they are taught.

One of the most important problems in OBE is the powerful curriculum design that gives experiential gaining knowledge of effectiveness of any curriculum may be measured via the procedure of coaching- getting to know and assessment of what students can genuinely do (i.e., learning consequences), after they may be taught. The OBE in particular attempts to undertake learning effects of the scholars in terms of understanding, skills, attitudes and values that suit the instantaneous social, economic and cultural environment of society. In accordance literature survey made, Figure-1 shows there are 3 types of OBE:

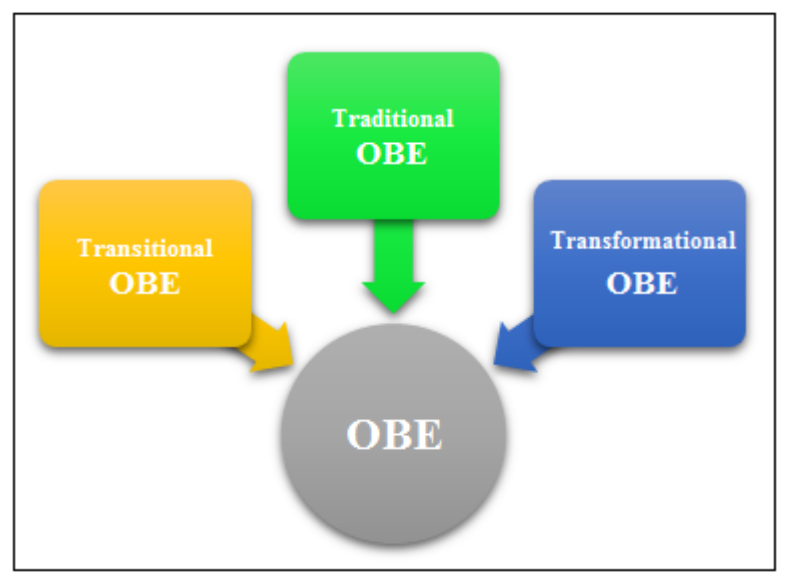

Fig-1: Three types of OBE- Traditional, Transitional, and Transformational OBE

a) Traditional or Conventional OBE which measures the mastering consequences in terms of students' mastery of the mounted curriculum.

b) Transitional $\mathbf{O B E}$ which measures the studying effects of college students in phrases of generic or higher order abilities such as important wondering, problem solving, conversation talents and teamwork.

c) Transformational $\mathbf{O B E}$ which measures the mastering results of students in terms of vast category of disciplinary understanding and competencies (i.e., multi-disciplined), customary talents, attitudes and values required by using the enterprise or society. Here is a desk displaying the variations among the traditional content material primarily based gadget to outcomes based totally device. 
Devasis Pradhan., J Adv Educ Philos, Feb, 2021; 5(2): 58-65

\section{Shift of Paradigm}

Aside from providing educators thoughts approximately the development of college students, it also informs them about the effectiveness in their coaching methodologies and strategies. Moreover, evaluation results in an OBE college are used as bases to enhance academic services and structures on an institutional level.
Paradigm Shift 1 - Teacher-Centered to LearnerCentered Approach

Evaluation in final results-based totally education require a shift in attitude of educators and educational leaders. The shift requires a turnaround of method from trainer-targeted to learner-focused training [3-6].

Table-1: Assessment: Traditional vs. OBE

\begin{tabular}{|l|l|}
\hline Traditional & OBE \\
\hline What are our (educators) practices & What our students have become and able to demonstrate \\
\hline Teaching (inputs, content) & Learning (demonstration of skills and competencies, outcomes) \\
\hline Teaching and Learning (TLA) as the end & Teaching and Learning (TLA) as the means to an end \\
\hline Practice determines the outcomes & Outcomes inform the practice \\
\hline $\begin{array}{l}\text { Learning is textbook/worksheet-bound and } \\
\text { teacher-centered }\end{array}$ & $\begin{array}{l}\text { Learning is learner-centered, the teacher facilitates and } \\
\text { constantly applies group work and team work to consolidate the } \\
\text { new approach }\end{array}$ \\
\hline $\begin{array}{l}\text { The teacher sees the syllabus as rigid and non } \\
\text { negotiable. }\end{array}$ & $\begin{array}{l}\text { Learning programmes are seen as guides that allow teachers to } \\
\text { be innovative and creative in designing their programmes. }\end{array}$ \\
\hline $\begin{array}{l}\text { Teachers are responsible for learning and } \\
\text { motivation depends on the personality of the } \\
\text { teacher. }\end{array}$ & $\begin{array}{l}\text { Learners take responsibility for their own learning and are } \\
\text { motivated by feedback and affirmation of their worth. }\end{array}$ \\
\hline
\end{tabular}

This call for for engineering courses has resulted to multiplied introduction of engineering institutions however due to the low pleasant of education they deliver, there was the hassle of unemployment of an intensive wide variety of the sparkling graduates. In standard the industry expects the subsequent ability units from the engineers:

- Mind-set (Sincerity, Can-Do, ownership / Motivation).

- Business Ethics/Honesty.

- Grooming/self belief.

- Communique capabilities.

- Preferred focus.

- Primary Managerial competencies (leadership, Teamwork, Time control, etc.).

- Primary income and customer support (most entry degree jobs require one of these).

- Area information.

From the above talent sets, the gentle talents are top maximum important element. To achieve the above talent units from the engineers, the industries expectation to educate and teach the scholars at Institutional give up as in step with requirement of the industries. This is why the outcome Base training (OBE) is most important rather than traditional schooling (TE).

\section{Paradigm Shift 2 -Being Outcomes-Minded}

Unnecessary to say, in final results-primarily based education framework everything need to be primarily based on outcomes. Accordingly, evaluation strategies and strategies ought to be consistent with the stated outcomes of training. In step with Bresciani [7], final results-based evaluation is a systematic and intentional technique. Which means that the checks used on this set-up are deliberately designed and administered in pursuit of consequences attainment. At the side of coaching and mastering sports, checks utilized in OBE lecture rooms must be constructively aligned with the effects that are predicted to be successfully demonstrated at unique stages and curricular ranges $[8,9]$.

Spady [10] certain 4 running ideas to be able to manual educators and educational leaders within the implementation of OBE. While carried out continuously, systematically, creatively, and concurrently the efforts of shifting to OBE can be almost guaranteed.

Basic operating principle of OBE:

a) Focus on Attainment: Educators need to be made conscious and aware of the effects of education each scholar ought to appear or exhibit on the direction level and that those outcomes on the study room stage are connected to the attainment of higher level consequences (i.e., application/institutional results and culminating results). Accordingly, on the preliminary level of instructional or path planning, the better consequences serve as guide for educators in defining and clearly stating the focal point of the course/difficulty.

b) Excessive Expectancy: As stated in the readability of attention precept, studying results at the route level are always linked to higher level effects. Those connections warrant educators from eliciting excessive degree of performance from college students. This stage of overall performance ensures that students successfully meet desired mastering 
effects set for a path, and therefore allow them to illustrate outcomes at higher stages.

c) Accelerated opportunity. The first and 2nd concepts importantly necessitate that educators deliver studentse getting to know studies at a complicated degree. In the manner, many college students may additionally find it hard complying with the requirements set for a path. This discourages educators from generalizing manifestations of found out conduct from students, considering that each pupil is a completely unique learner. Thus, an accelerated opportunity ought to be granted to students in the manner of mastering and extra importantly in assessing their overall performance. The expansion of possibility may be considered multidimensional.

\section{Keys concept of $\mathrm{OBE}$}

OBE addresses the following key questions:

What do we want the students to have or be able to do? How can we best help students achieve it?

How will we know whether they students have achieved it?

How do we close the loop for further improvement (Continuous Quality Improvement (CQI))?

\section{Benefits of OBE}

1) More directed \& coherent curriculum.
2) Graduates will be more "relevant" to industry \& other stakeholders (more well rounded graduates)

3) Continuous Quality Improvement (CQI) is in place.

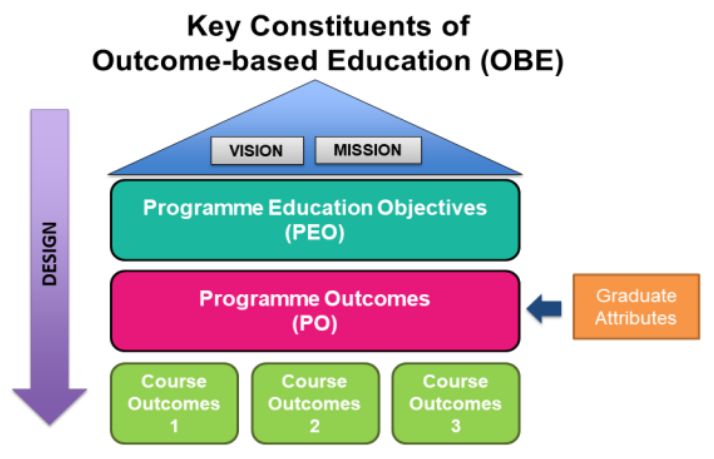

Fig-2: Key features of OBE

\section{OBE Frame Work}

The OBE Framework is a paradigm shift from conventional training gadget into OBE gadget here there's greater attention on software and route outcomes. Additionally for the instructional machine to feature successfully, OBE framework is identified. It ensures that curriculum, coaching and studying strategies, and evaluation equipment are continuously better through an evaluation procedure Figure-3.

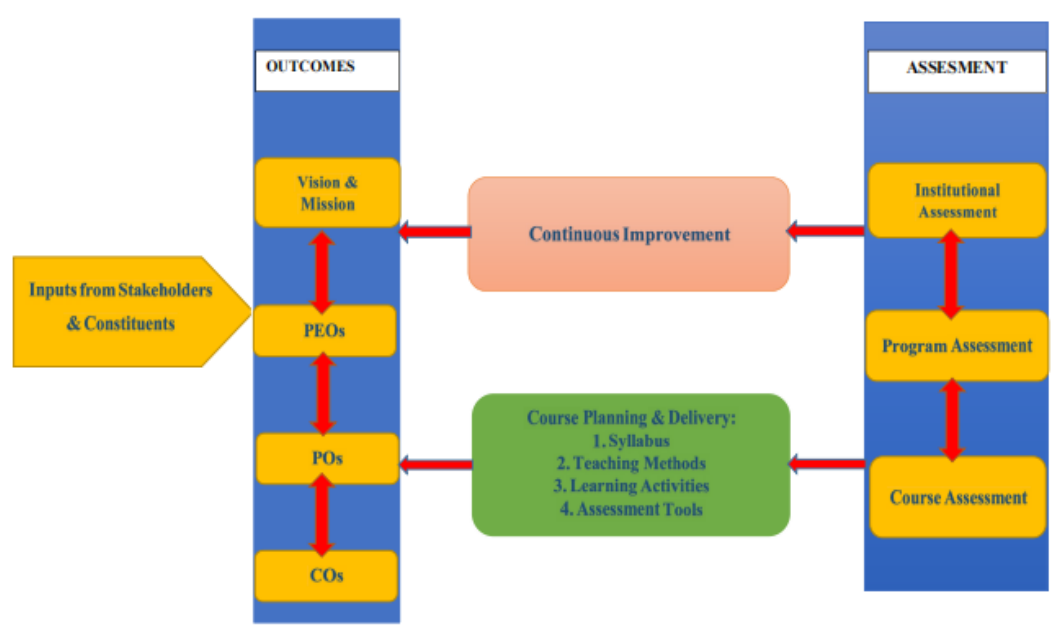

Fig-3: OBE Framework

The OBE framework as shown in the Figure-3. OBE Implemented with the following components:

- Vision, and Mission

- PEOs

- $\quad$ POs

- PSOs

- $\mathrm{COs}$

\section{Course Outcomes}

Course outcomes are the statements that describe what students are expected to realize, and be able to do at the of entirety of the direction $[11,12]$. They relate to the skills, information, and behavior that scholars collect on finishing touch of the direction. The path consequences of all of the guides in a $4 \mathrm{yr}$ engineering course are mapped to application consequences to gain the graduate attributes of NBA. The course outcomes for principle of communication system offered in fifth semester of electronics \& communication engineering framed as per Blooms Taxonomy Level given in Table-2. 
Devasis Pradhan., J Adv Educ Philos, Feb, 2021; 5(2): 58-65

Table-2: Course Outcomes of principle of communication system with subject code 18EC53

\begin{tabular}{|l|l|}
\hline COs & Statements \\
\hline CO53.1 & $\begin{array}{l}\text { Explain the fundamental concept of different modulation and demodulation techniques used in } \\
\text { analog communication. }\end{array}$ \\
\hline CO53.2 & Compute various parameters related analog communication system. \\
\hline CO53.3 & Analyze the performance of the analog communication system in the presence of noise. \\
\hline CO53.4 & Analyze and compute performance of digital formatting processes with quantization noise. \\
\hline
\end{tabular}

\section{Program Educational Objectives (PEOs)}

PEOs are the statements that describe what college students are predicted to understand, and be able to do at the final touch of the route $[11,12]$. They relate to the capabilities, information, and behavior that students collect on crowning glory of the route. The course results of all the publications in a four year of engineering course are mapped to application effects to obtain the graduate attributes of NBA. Application educational objectives (PEO) is defined as features or precise goals describing predicted achievements of graduates in their career and professional life after graduation. Those goals are aligned with the visionmission declaration of the branch and are described in collaboration with the stakeholders from the enterprise partners, students, parents, alumni, school and administration [13, 14]. The PEOs may be assessed 3 (three) to five (5) years after the students graduated from university via a tracer have a look at and employers questionnaire surveys. The records obtained from the assessment might be used as basis for the development of the prevailing PEOs.

\section{Program Outcomes (POs)}

At the heart of OBE are the Graduate Attributes. The Graduate Attributes, also referred to as Program Outcomes, stated in Washington Accord, which are given below [15].

1) Engineering knowledge: Apply the knowledge of mathematics, science, engineering fundamentals, and an engineering specialization to the solution of complex engineering problems.

2) Problem analysis: Identify, formulate, research literature, and analyze complex engineering problems reaching substantiated conclusions using first principles of mathematics, natural sciences, and engineering sciences.

3) Design / development of solutions: Design solutions for complex engineering problems and design system components or processes that meet the specified needs with appropriate consideration for the public health and safety, and the cultural, societal, and environmental considerations.

4) Investigation: Use research-based knowledge and research methods including design of experiments, analysis and interpretation of data, and synthesis of the information to provide valid conclusions

5) Modern tool usage: Create, Select, and apply appropriate techniques, resources, and modern engineering and IT tools including prediction and modeling to complex engineering activities with an understanding of the limitations.
6) The Engineer and Society: Apply reasoning informed by the contextual knowledge to assess societal, health, safety, legal and cultural issues and the consequent responsibilities relevant to the professional engineering practice.

7) Environment and sustainability: Understand the impact of the professional engineering solutions in societal and environmental contexts, and demonstrate the knowledge of, and need for sustainable development.

8) Ethics: Apply ethical principles and commit to professional ethics and responsibilities and norms of the engineering practice.

9) Individual and team Work: Function effectively as an individual, and as a member or leader in diverse teams, and in multidisciplinary settings.

10) Communication: Communicate effectively on complex engineering activities with the engineering community and with society at large, such as, being able to comprehend and write effective reports and design documentation, make effective presentations, and give and receive clear instructions.

11) Project management and finance: Demonstrate knowledge and understanding of the engineering and management principles and apply these to one's own work, as a member and leader in a team, to manage projects and in multidisciplinary environments

12) Life-long learning: Recognize the need for, and have the preparation and ability to engage in independent and life-long learning in the broadest context of technological change.

\section{Program Specific Outcomes (PSOs)}

Import knowledge of technology as basic goal of schooling. A scientific mindset to make students create open minded and curiosity. To have know-how about various plant companies from decrease to higher agencies. To make the students aware of biodiversity conservation and sustainable use of plants. Practice the knowledge of primary technological know-how, life sciences and fundamental system of plant to look at and examine plant shape. Develop competencies in sensible work experiments, equipment's and laboratory use in conjunction with series and interpretation of organic substances and records.

\section{Pedagogical Processes in Engineering Programme}

Innovation is ready doing beneficial matters in a different way: converting novel ideas and methods into answers that meet new desires, or adding large cost 
Devasis Pradhan., J Adv Educ Philos, Feb, 2021; 5(2): 58-65

to mounted products and services. In engineering schooling, new technological and practice necessities necessitate curriculum innovation, while innovation in instructional exercise can enhance college students' learning and college productiveness. So, this intention can be accomplished by way of the pedagogical method and also by means of introducing advance pedagogy in engineering. The important thing component of enhance-pedagogy is micro-teaching, where each topic is analyzed and introduced with the mapping of real international philosophy.

In technology and engineering training, this consists of theoretical records of phenomena and propositions and their justifications. The learning of the packages to everyday existence and engineering is, of direction, of important importance. The problem of an engineering educator need to be constructed of, no longer simplest of instructional studies, however also of a extensive revel in of operating in the industry or as a researcher in which the information has been applied, confirmed and subtle in exercise. The output based deliverable content (OBDC) is despatch-ed to the pupil (magnificence sensible) in advance so that scholar can accumulate expertise prior to the class initiation which guarantees deep getting to know (FLIP Learning) through asking many questions to the instructor as well as fellow pals. The effect of OBDC is to beautify skill due to the fact in industry talent is extra crucial than understanding. In our EPOBE, the complete GA displays in PEO and Bloom's revised taxonomy is used to layout PEO.

\section{OBE Assessment}

Assessment can provide direct or indirect measures of scholar learning.

- Direct measures require students to demonstrate their achievement and often involve quantitative dimension techniques.

- Indirect evaluation is primarily based on critiques.

Direct proof of pupil overall performance or attainment relies upon direct scrutiny or examination of pupil performance or attainment for individual students. These strategies assist you to accumulate the evidence of pupil mastering or fulfillment immediately from students and the diverse works they publish to you (assignment, examination, term paper, challenge, Laboratory, exams, Quizzes and etc) [16, 17]. Indirect proof of scholar achievement calls for that faculty infer real scholar skills, understanding, and values rather than have a look at direct evidence of getting to know or fulfillment. Oblique strategies offer the views of students, college or other individuals who are concerned with the route or software or group, along with alumni. Table- 3 shows the brief of direct and indirect assessment tool to evaluate OBE frame work.

Table-3: Assessment Tools for OBE Frame Work

\begin{tabular}{|l|l|}
\hline Direct Assessment & Indirect Assessment \\
\hline $\begin{array}{l}\text { Student work (artifacts) that are embedded in the course (i.e., } \\
\text { assignments, exams, projects, research papers, final papers, oral } \\
\text { presentations /exams, recital, play, performance) }\end{array}$ & Departmental survey \\
\hline Comprehensive exams (for the degree) & Exit interview \\
\hline Standardized tests developed within the program & Survey of current students \\
\hline $\begin{array}{l}\text { National standardized exams (i.e., GRE subject exams, National } \\
\text { Major Field Achievement Tests, ETS field tests, Collegiate Learning } \\
\text { Assessment, Collegiate Assessment of Academic Proficiency, Skills) }\end{array}$ & Survey of faculty members \\
\hline Certification, licensure exams & Survey of co-op coordinators \\
\hline Senior thesis or major project & Alumni survey \\
\hline $\begin{array}{l}\text { Poster presentation, Case studies, Reflective journals, Capstone } \\
\text { projects, Internal /external juried review of performances and } \\
\text { exhibitions }\end{array}$ & Employer survey \\
\hline External examiners/peer review & Focus group and Job placement statistics \\
\hline Evaluations with rubrics & $\begin{array}{l}\text { Percentage of students who participate in } \\
\text { Co-op, Internships, Service Learning, etc. }\end{array}$ \\
\hline
\end{tabular}

\section{Attainment of Outcomes}

The process of attainment of COs, POs and PSOs starts off evolved from writing appropriate COs for each route of the program from first year to the end of the program. The course effects are written by using the respective students. Then, a correlation is set up among COs and POs in a set scale price for example, 1 being the mild (low), 2 being slight (medium) and three being massive (high). A mapping matrix is ready on this regard for each direction in the software. The general attainment of consequences of a application
(POs) is computed through including direct attainment and oblique attainment values in a hard and fast percentage and compared with the set price. Any deviations from the set values, then the device ought to be progressed so that to attain the set fee. This must be achieved continuously until the attainment of set value. This is referred to as the non-stop improvement and also the electricity of the OBE. Students will undergo rigorous training on selected set of courses and will be taking up continuous internal evaluation (CIE) tests given by the course instructor and semester end 
Devasis Pradhan., J Adv Educ Philos, Feb, 2021; 5(2): 58-65

examination (SEE) conducted at institution level comprising of both internal and external evaluators.

\section{Attainment of POs}

One of the parameters to measure the attainment of POs is thru evaluation of attainment of a predefined set of COs. Every course has described set of COs which can be mapped to the POs and they may be used to provide quantitative measurement of how nicely direction consequences are carried out. The CO mapping is performed quantitatively and mapping matrix is made to be had inside the course syllabi. Assembly the COs through the method of assessment via examination machine is a clean benchmark for attainment of POs. Oblique size involves the route-stop survey, venture primarily based getting to know tests, accomplishing open ended experiments, taking up competitive examination for better education etc.

\section{Attainment of COs}

COs are evaluated based on continuous internal evaluation (CIE) as a right away degree and Course end Survey (CES) as an indirect measure. To provide an explanation for the system followed for attainment calculation, two guides examples were taken into consideration. The entire attainment in phrases of the students' performance toward attaining the COs is measured the usage of both direct and indirect assessment gear. The direct assessment includes his performance measures in CIE and SEE (Semester End Examination).

\section{Difficult in Implementation}

Whilst implementing OBE we should clear positive obstacle that we may additionally face:

a. The unclear and ambiguous setting of sure results both for the teacher, pupil or each avert student achievement and teacher contribution inside the curriculum.

b. The lecturers' unawareness of the curriculum's final results will limit the collaboration and cooperation among the faculties to attain a common purpose; developing a state of traditionalism and faculty resistance.

c. The mistaken assessment device that doesn't match the aimed outcome or that doesn't take into account the variety in scholar's success.

\section{Steps for Implementation of successful OBE in Engineering Programme}

For a successful of OBE program collaborative attempt from administrators, educators, figure, teachers and students ought to be sought to guarantee a a hit making plans and implementation and to assure dedication and decrease resistance.

The simple traits and ideas for OBE implementation could include:

a. A clean institutional endorsed project
announcement that displays commitment to fulfillment for all the students and gives the way for translating that dedication into action.

b. Truely described 'go out outcomes' that issued to articulate the curriculum framework of this system and that deliver what students have to exhibit earlier than they graduate.

c. Engagement of massive, complicated and geographically dispersed faculty staff in an extended length of distinctly collaborative, crossdisciplinary communicate, modern thinking and planning to assure ownership and full commitment of the institution.

d. A device of instructional choice making and transport that employs a ramification of techniques to guarantee successful demonstration of all outcomes and to provide a couple of risk for students to be successful.

e. A couple of educational and evaluation techniques that meet the needs of every pupil with allowing stipulated time and help for each scholar to attain the maximum capacity.

f. A criterion-referenced system of assessment and an ongoing device of improvement applications that ensure workforce accountability, powerful management and body of workers collaboration with a information base of big, visionary consequences for all students, plus key signs of institute effectiveness, that is used and up to date regularly to enhance situations and practices affecting pupil and workforce success $[14,18]$.

\section{CONCLUSION}

The EPOBE structure is related to soft-talent, engineering training framework primarily based on Graduate Attributes, OBE framework and strengthen engineering pedagogy. The educations are supplied consistent with the macro-degree curriculum that is designed based totally on OBE, but colleges use to deliver the content material at micro-stage. Increase Pedagogy is the platform to increase micro-degree teaching teachers, dad and mom and college students far from grades so that gaining knowledge of results are accorded due weight age inside the evaluation structures. A success implementation of consequences primarily based engineering education is feasible most effective with the concerted efforts of all the stake holders - college students, instructors, employers and the authorities - as each considered one of them stands to benefit out of it. The OBE implementation allows them which will evolve to soak up the engineering issues addressing the present day problems and provide Engineering solution.

OBE is an educational approach considered in making plans, enforcing and assessment of curricula in preference to an event going on in the curricula. It promises excessive degree of gaining knowledge of for all students based totally at the achievement of really unambiguous effects with attention to the 
appropriateness of each learner's development degree and assuring energetic and experienced-based learning.

\section{REFERENCE}

1. Tucker, A. (2004). Our knowledge of the past: A philosophy of historiography. Cambridge University Press.

2. Harden, R. M., Crosby, J. R., \& Davis, M. H. (1999). An introduction to outcome-based education. Med Teacher, 21(1).

3. Bresciani, S., Thrassou, A., \& Vrontis, D. (2012). Human resource management-practices, performance and strategy in the Italian hotel industry. World Review of Entrepreneurship, Management and Sustainable Development 3, 8(4), 405-423.

4. Bresciani, S., \& Eppler, M. J. (2009). The risks of visualization. Identität und Vielfalt der Kommunikations-wissenschaft (2009), 165-178.

5. Ramoroka, T. (2006). Nogeng fights. Kutlwano, 47(10), 24-25.

6. Niebuhr, R. (1996). The Nature and Destiny of Man: A Christian Interpretation: Human Nature. Westminster John Knox Press.

7. Bresciani, M. J. (2006). Outcomes-based academic and co-curricular program review: A compilation of institutional good practices. Stylus Publishing, LLC.

8. Biggs, J. B. (2011). Teaching for quality learning at university: What the student does. McGraw-hill education (UK).

9. Biggs, J., \& Tang, C. (2007). Teaching for quality learning at university Maidenhead. Berkshire, UK: McGraw-Hill Education.
10. Spady, W. G. (1994). Outcome-Based Education: Critical Issues and Answers. American Association of School Administrators, 1801 North Moore Street, Arlington, VA 22209 (Stock No. 21-00488; $\$ 18.95$ plus postage).

11. Spady, W. (1993). Outcome-based education. Australian Curriculum Studies Association.

12. Rubin, S. E., \& Spady, W. G. (1984). Achieving Excellence Through Outcome-Based Instructional Delivery. Educational Leadership, 41(8), 37-44.

13. $\mathrm{Vu}, \mathrm{V}$. T. (2015). Outcome-based quality management in higher education: An approach to meeting societal needs. International Journal of Development Research, 5870-5874.

14. Hilario, J. S. (2015). Using outcomes-based education (OBE) in the teaching and learning of community and public health with related learning experience. Asian Journal of Educational Research, 3(3).

15. Harden, R. M., Crosby, J. R. \& Davis, M. H. (1999). AMEE Guide No. 14: Outcome-based education: Part 1-an introduction to outcome based education, Medical Teacher, 21, 7-14.

16. Sanjay, J. (2015). CEO, InPods, Siliconindia: Magazine on Learning Analytics for OutcomeFocused Education, Startup of the year 2015.

17. Blom, A., \& Saeki, H. (2011). Employability and skill set of newly graduated engineers in India. The World Bank.

18. Mehdi, R. A., \& AbouNaaj, M. S. (2013). Academic program assessment: A case study of a pragmatic approach. Creative Education, 4(01), 7181. 